Teknokultura. Revista de Cultura Digital y Movimientos Sociales

ISSNe: 1549-2230

\title{
Capitalismo digital, ¿cuáles son las posibles salidas? Traducción e introducción a cargo de Ekaitz Cancela y Aitor Jiménez ${ }^{1}$
}

\author{
Evgeny Morozov ${ }^{2}$ \\ Recibido: 1 de febrero de 2021 / Aceptado: 1 de abril de 2021 Open peer reviews
}

Resumen. Texto basado en la ponencia ofrecida por Evgeny Morozov el 15 de diciembre de 2020 en el contexto de las jornadas 'Soberanía tecnológica: Democracia, datos y gobernanza en la era digital Alternativas al capitalismo desde el sur' organizadas por el Instituto 25 de marzo para la Democracia. Transcripción, traducción e introducción a cargo de Ekaitz Cancela y Aitor Jiménez.

Palabras clave: capitalismo; Hayek; Marx; modo de descubrimiento; modo de producción.

\section{[en] Digital capitalism, what are the possible alternatives? Translation and Introduction by Ekaitz Cancela and Aitor Jiménez}

\begin{abstract}
Article based on the presentation given by Evgeny Morozov at the 'Soberanía tecnológica: Democracia, datos y gobernanza en la era digital Alternativas al capitalismo desde el sur' conference, on December 152020 , event organised by the Instituto 25 de marzo para la Democracia. Transcription, translation and introduction by Ekaitz Cancela and Aitor Jiménez.
\end{abstract}

Keywords: capitalism; Hayek; Marx; mode of discovery; mode of production.

Sumario. 1. Introducción de los traductores. 2. Ponencia

Cómo citar: Morozov, E. (2021). Capitalismo digital, ¿cuáles son las posibles salidas? Traducción e introducción a cargo de Ekaitz Cancela y Aitor Jiménez. Teknokultura. Revista de Cultura Digital y Movimientos Sociales, 18(2), 211-217. http:// dx.doi.org/10.5209/TEKN.74059

\section{Introducción de los traductores}

En un momento de crisis en que las fuerzas progresistas se encuentran confundidas en el análisis sobre las tecnologías digitales y, aún más, se muestran incapaces de integrar dichas herramientas en una agenda progresista emancipadora, la visión de Evgeny Morozov apunta hacia formas nuevas para pensar en alternativas al capitalismo. Bien entendida, dejando de lado la premura en que tuvo lugar la conferencia transcrita a continuación, el aporte de pensar lo nuevo desde categorías antisistémicas es la 'praxis' de la que el intelectual hace gala. La aportación principal de este texto es que el autor introduce por primera vez la idea del 'medio de descubrimiento', en clara oposición hacia el 'medio de producción' propiamente marxista. Este contraparadigma puede tener implicaciones importantes para la lucha política del presente, permitiendo evidenciar las flaquezas de la línea de flotación argumental de los capitalistas, atrapados en la herencia del pensamiento neoliberal surgido en los albores de la Guerra Fría en oposición al comunismo, al tiempo que otorga una ventaja a los movimientos que tratan de trascender este sistema. Ello se debe a que no sólo se expone una ideología de manera clara, ahí donde menos visible es y también donde más puede dinamitarse, sino porque abre una línea teórica para pensar en cómo desarrollar tecnologías para transformar la realidad, una tan distópica como la que traen los efectos del cambio climático.

La conferencia comienza con una exposición sobre la manera en que las tecnologías se insertan en las lógicas estructurales del sistema capitalista, en lugar de inaugurar una nueva era digital o espolear dinámicas históricas distintas. Para el autor, la corriente intelectual que viene teorizando el llamado capitalismo digital forma parte de un 'nicho intelectual' que ha realizado más esfuerzos analísticos en entender el apellido de este sistema que en ilustrar sus lógicas intrínsecas: salvaje competencia inter-capitalista, búsqueda de rentabilidad a largo plazo y aprovechar las tendencias hacia crisis como la de 2008 para expandir los espacios de acumulación de capital. Por ejemplo, sostiene Morozov, empresas como Uber no representan el culmen de una suerte de eficiencia algorítmica derivada del correcto uso de las tecnologías digitales,

Instituto 25 de marzo para la Democracia.

2 Fundador de The Syllabus, plataforma de curación de conocimiento (Bielorussia) 
sino lo que Marx hubiera denominado como la absoluta irracionalidad del capital: los enormes gastos de empresas como Uber en tecnologías de autoconducción, cerca de 20 millones mensuales, forman más bien parte de una lógica extremadamente ineficiente asentada en quemar dinero con la mirada puesta en perspectivas o expectaciones futuras. La necesidad de los grandes inversores de poner dinero a circular en sectores rentables en un momento de crisis económica explica el éxito de esta empresa, que ha conquistado el mercado a base de ofrecer viajes a precios bajos derivados del enorme apoyo de fondos soberanos como Vision Fund de SoftBank. No existen aumentos en la eficiencia o sistemas autónomos orientados a mejorar la movilidad de las ciudades, sino grandes capitales que entienden estos territorios geográficos como en meros espacios para la mercantilización de la vida en común. Si la presencia de Uber en las metrópolis desemboca en un aumento del tráfico y peores políticas urbanas, como muchos estudios sugieren, desde luego eso no es problema de los gerifaltes de Silicon Valley.

Para entender estos cambios estructurales y epistémicos, Evgeny Morozov desarrolla un paradigma del capitalismo alternativo al de la primacía del modo de producción e ilustra que, tal y como la defienden los marxistas ortodoxos, este es un concepto limitado para entender la forma en que los datos producen valor. Trascendiendo intelectualmente los distintos debates académicos sobre el trabajo digital, el autor sostiene que la extracción de valor en la economía digital no se asienta sobre la mera actividad productiva, es decir, la intervención en la naturaleza mediante desarrolladas herramientas técnicas. Más bien al contrario, la enorme cantidad de datos que generan los ciudadanos cuando interactúan con las plataformas extraen valor de buena parte de las acciones de la vida cotidiana, transformándolos después en activos que procesan las inteligencias artificiales o los algoritmos de empresas privadas para conseguir beneficios económicos. Como explica el pensador bielorruso, nada de ello es compresible ateniéndose a la producción y al ejercicio de la actividad productiva en el sentido estricto de la definición.

A la hora de trascender este marco de pensamiento, Morozov toma como referencia la definición del capitalismo de autores neoliberales como Friedrich Hayek o Ludvig von Mises. De acuerdo con las tesis sostenidas por estos neoliberales, el capitalismo sería un modelo de descubrimiento de soluciones a los problemas del sistema que tiene lugar a través del mercado y el sistema de precios. El posicionamiento de Morozov va más allá y dilucida las debilidades de este paradigma a la hora de explotar toda la potencialidad y el conocimiento colectivo que facilitan las tecnologías digitales, es decir, las promesas económicas del capitalismo nunca se cumplirán porque no tienen en cuenta factores distintos a los económicos, al igual que los viejos y los nuevos marxistas. Esto es, la búsqueda irrefrenable del interés individual y el egoísmo que fomentan las lógicas neoliberales de competencia impedirían emplear el intelecto colectivo de manera altruista para afrontar de manera conjunta los problemas de la sociedad, establecer métodos de coordinación social distinta a los del mercado $\mathrm{y}$ descubrir formas radicales de responder al presente.
Según nuestro autor, si los neoliberales han conseguido mantener una relativa ventaja teórica y política respecto a sus enemigos en la izquierda, esto se debe a cómo han logrado presentar las cuestiones más políticas del capitalismo desde la Guerra Fría, momento en que la 'intelligentsia’ izquierdista quedó atrapada en el paradigma de la mera planificación.

Más allá de ofrecer respuestas a la distribución de los recursos económicos, autores como Hayek lograron institucionalizar el descubrimiento de conocimiento y experiencias sensoriales nuevas sobre el mundo que nos rodea, de las innovaciones más mundanas del día a día, mediante la aplicación de los mecanismos mercantiles. Podría decirse que el mero hecho de desarrollar aplicaciones tecnológicas para dar respuestas a los problemas sociales, políticos, económicos o culturales existentes, aquello que en una etapa intelectual más temprana Morozov denominó en 2013 como 'solucionismo tecnológico', tan sólo era la forma en que el capitalismo justificaba su predominio sobre otras alternativas no sometidas a las lógicas del mercado. Descubrir nuevos bienes o servicios de consumo, métodos de producción más eficientes y autoritarios o maneras de mercantilizar los comunes, como es el caso de los datos, sería aquello que otorgaría al neoliberalismo la hegemonía necesaria para perpetuar el sistema capitalista. De nuevo, no es la producción el concepto determinante para entender la realidad, o al menos como la entendería el materialismo histórico, sino toda una plétora de instintos naturales, comportamientos y actividades humanas no categorizables mediante el 'reduccionismo de lo productivo'.

En último término, Evgeny Morozov trata de alertarnos sobre las enormes posibilidades contenidas en las tecnologías digitales para compartir la información necesaria que permita a los ciudadanos comprender la realidad y diseñar formas para institucionalizar el descubrimiento de lo nuevo de manera en que las agendas radicales sean implementadas. Hasta ahora, argumenta, estas iniciativas no han triunfado porque no son rentables, criterio último por el que se rige el capitalismo. Por tanto, los descubrimientos han sido monopolizados por start-ups que acuden al mercado de valores o llevaban a cabo rondas de financiación gracias a fondos de capital riesgo, fondos de inversión o fondos soberanos. Prueba de ello es de nuevo el ejemplo de Uber, cuyo accionista principal es un fondo de 90.000 millones (Vision Fund) que ha recibido la mitad del capital del fondo soberano de Arabia Saudí. Experimentos alternativos para institucionalizar el conocimiento (el autor utiliza el ejemplo de Science Hub) sólo pueden encontrarse en la actualidad de manera residual y su desarrollo se encuentra bloqueado debido a la primacía de las soluciones ofrecidas por las start-ups y los grandes capitales que las respaldan. Desde luego, esta es una conceptualización del término solucionismo (filosófica en grado máximo, toda una declaración de intenciones respecto al viejo Marx) mucho más compleja que la ofrecida por el autor hace una década. Podría afirmarse que Morozov ha realizado toda una crítica a la crítica de la crítica de la economía política a fin de dilucidar un método dialéctico capaz de dotarnos de las herramientas teóricas necesarias para emancipar- 
nos alegremente del pasado (ergo de la modernidad capitalista).

Hacia el final de su exposición, Morozov se pregunta cómo debieran entenderse los métodos de descubrimiento desde una concepción antisistémica y deja entrever cuál debe ser una agenda transformadora. Esta debiera institucionalizar dicha práctica de una manera en que se creen estructuras perpetuas de revisión y descubrimiento de nuevos hechos sobre el mundo. Ello significaría crear mecanismos estatales, a saber, políticos, para aprovechar la actividad social y la creatividad humana de la que hacemos gala diariamente, desestabilizando así los pilares del orden capitalista. En efecto, con el objetivo de construir formas nuevas de capturar el valor y ponerlo al servicio de la sociedad, no de la acumulación capitalista. Según sugiere el autor, el mejor ejemplo para ilustrar la necesidad de llevar a cabo intervenciones políticas que permitan descubrir nuevas formas de vida en sociedad es enfrentar colectivamente el calentamiento global, desatado por los combustibles fósiles, y encontrar salidas a la aniquilación de la propia especie humana.

En definitiva, pese a su abstracción y denotada falta de claridad, de este texto se desprende una descripción empírica del capitalismo en base a las categorías que operan en el breve siglo XXI, no de aquellas concepciones histórica marxistas sin ninguna aplicación contemporánea para comprender el presente. Nos encontramos ante la primera exposición de un método pionero, y distinto al marxista, que trata de dotar a los movimientos progresistas de izquierda de una caja de herramienta teórica capaz de plantar batalla a los neoliberales en nuestro tiempo histórico. No hace falta especular mucho, aunque tal vez sí hacer gala de un optimismo mayor al del propio autor, para afirmar que la conferencia que a continuación se expone es la primera declaración pública de unas ideas, las de Evgeny Morozov, que darán de nuevo la vuelta al mundo, aunque esta vez para inspirar las revueltas antisistémicas que están por llegar.

\section{Ponencia}

En primer lugar, creo que debéis ser pacientes con mi línea argumental. Como Ekaitz ha mencionado, en los últimos años he estado trabajando en un libro y parece que está en las etapas finales, por lo que debería publicarse, o al menos estar terminado, relativamente pronto. Voy a tratar de condensar algunas de esas ideas y entrar en el meollo del problema. No obstante, debo advertir que muchos de estos pensamientos aún están siendo refinados y que probablemente aparezcan de una forma ligeramente distinta.

Los organizadores me han pedido que hable sobre cómo podemos ir más allá o, de manera más concreta, trascender al capitalismo digital. Creo que vale la pena reflexionar un poco sobre el término 'capitalismo digital' y preguntarnos si en realidad este es un marco válido para el análisis. Creo que debiéramos tener mucho cuidado a la hora de crear una especie de gueto político e intelectual que entiende el capitalismo digital como un sistema que opera de acuerdo con su propia lógica. El capitalismo digital no es algo del capitalismo más antiguo, es decir, sus lógicas o mecanismos no funcionan de manera perfecta (y Silicon Valley ha llegado para disrumpirlas). Existe además una tendencia intelectual a tratar esta nueva esfera digital como algo excepcional y exenta de la lógica del capital, las finanzas u otros desarrollos económicos más amplios que han tenido lugar en los últimos cincuenta años. En términos analíticos, este ejercicio es bastante poco sano. Lo que tenemos que hacer es encontrar formas de reinscribir este capitalismo digital en una especie de narrativa histórica, cultural y política sobre el capitalismo en sí mismo.

No creo que sea hazaña particularmente complicada, pero creo que es fundamental que pongamos a prueba esa idea de que hay algo estructuralmente diferente acerca de la digitalización que de alguna manera ha dado lugar a una nueva era. En mi opinión, esta es una forma inútil de pensar en el capital porque, esencialmente, tiende a convertir muchas de las características contingentes de nuestra sociedad digital actual en una especie de celebración involuntaria de la generalidad de Elon Musk o Jeff Bezos. Déjenme poner un ejemplo: si observamos el auge de compañías como Uber y Airbnb, entonces parece obvio que puedes contar dos historias sobre la forma en que lograron destruir a proveedores tradicionales de servicios [competidores], por ejemplo, en áreas como el transporte. Es obvio que la historia que a Uber le gustaría contar sobre sí misma es una donde el capitalismo digital es mucho más eficiente, impermeable y tal vez más sostenible, al menos en cuanto a lo que se refiere a las emisiones contaminantes, que el viejo capitalismo. Y aquí es donde aparecen estas narrativas sobre la digitalización como llave que abre todas las puertas; como si Uber y las empresas del estilo fueran algo así como una vanguardia que lidera la ola de la digitalización. Esta es una historia con una narrativa determinada sobre el capitalismo digital $\mathrm{y}$, al aceptarla, contribuimos de una manera u otra a la reificación del capitalismo digital como un fenómeno con leyes distintas al capitalismo de siempre.

Ahora bien, la historia alternativa que podemos contar sobre Uber es que los bajos precios y costes que ofrecen estas plataformas no se derivan de su dominio sobre las artes de la automatización y la digitalización, sino simplemente a una cuestión sobre cómo se ha configurado esta firma dentro del capitalismo global, especialmente después de la crisis financiera de 2007 y 2008. Digamos que entonces existía una gran cantidad de capital inactivo que realmente no podía ir a ningún otro lado, es decir, no era capaz de fluir fácilmente hacia el mercado de bonos porque las tasas de interés son bajas o negativas; tampoco hacia la producción, pues la industria tiene muchos problemas y afronta dosis elevadas de incertidumbre para asegurar sus ganancias. Por lo tanto, el capital encontró una salida viable en empresas como Uber o Airbnb. Al mismo tiempo, debido a varias razones que tienen que ver con la necesidad de mantener las valoraciones de estas empresas artificialmente altas, puede decirse que se han quemado miles de millones de dólares cada año con el objetivo de subsidiar los viajes baratos de los pasajeros en coches de Uber. 
Si entendemos estos procesos desde la perspectiva descrita, la historia que encontramos sobre el llamado capitalismo digital es muy diferente. Esta es una narración donde las tecnologías están intrínsecamente vinculadas a la crisis del capitalismo de 2007, a la dinámica habitual del capital de buscar las salidas más rentables y a la necesidad de mantener cotizaciones en bolsa infladas de manera artificial. En resumen, una historia sobre el capitalismo digital que no es esa narrativa sobre la hiper eficiencia que introducen los algoritmos, sino con todo lo contrario: una historia de la hiper ineficiencia de muchas de estas empresas, las cuales existen porque las fuerzas del capital global no tenían otra salida a la que acudir después de la crisis de 2007. Esta historia sale a la luz ocasionalmente cuando tienes colapsos espectaculares como el de WeWork, una empresa que fue celebrada por capitalistas de riesgo, fondos soberanos y los medios de comunicación internacionales porque su precio en bolsa se había disparado increíblemente. No obstante, la realidad era que sus ganancias no existían. Estos ejemplos nos dice que debemos tener mucho cuidado o las empresas capitalistas se saldrán con la suya e impondrán la narrativa que más les interesa contar.

Por eso, la pregunta que realmente creo tenemos que hacernos es ligeramente diferente, y va más allá del capitalismo digital como tal. Estamos en 2020, vivimos en Europa y nos exponemos a una cantidad considerable de factores y limitaciones. Por un lado, la política tiene un gran interés en continuar tanto con los procesos de subcontratar y delegar al sector tecnológico cada vez más responsabilidad como en realizar funciones que antes eran abordadas por el Estado, la burocracia o la sociedad civil. Durante más de una década, mi trabajo se ha centrado en demostrar y describir dicho proceso. Hasta cierto punto se suponía que el término 'solucionismo' cubría eso, es decir, la realidad no contada sobre la constante delegación de funciones. No obstante, esta no es la única condición que debemos poner sobre la mesa antes de pensar cómo podemos salir del capitalismo digital, por utilizar este término durante un instante.

Creo que la otra condición importante que debemos señalar, al margen del solucionismo, es el hecho de que la izquierda no tiene una visión de cómo sería un futuro no capitalista y de qué tipo de futuro no capitalista quiere. Hasta que no seamos capaces de articular esa idea y pensar la manera en que debiera diferir de las alternativas anteriores, hasta cierto punto construidas por la izquierda en la Unión Soviética u otros lugares, no llegaremos a una visión constructiva sobre qué papel podría desempeñar la tecnología en ese proceso. También careceremos de orientación normativa alguna sobre cómo la infraestructura tecnológica actual difiere de la que realmente necesitamos para dicho proyecto político utópico. Por eso, la fruta más fácil de coger, aquella que es más tentadora para la izquierda, tiene que ver con una agenda puramente defensiva y hasta cierto punto regulatoria. Esto es lo que está sucediendo en Europa. El problema es que la izquierda no tiene ningún plan, no solo en lo relacionado con la tecnología, sino en lo que respecta al futuro en general. Y seré feliz defendiendo esta provocación tanto como sea necesario. Básicamente, la izquierda se sube al tren de la regulación e intenta atar las manos de las Big Tech, hacer que paguen impuestos, que cumplan con los reglamentos de privacidad, con el derecho al olvido, o atarlos a los objetivos e imperativos del nuevo acuerdo ecológico (Green New Deal) y así sucesivamente.

Al parecer, en la medida en que este es un proyecto razonable no hay necesidad de preocuparse por suscribir algunas de esas declaraciones. En mi opinión, este no es realmente un proyecto para la izquierda, sino que hasta cierto punto se puede decir que es una consecuencia de ciertas respuestas o reflejos socialdemócratas, si se quiere, que todavía están presentes en nuestro body politic. En resumen, creo que la izquierda se enfrenta a toda una serie de elecciones u opciones y en torno a estas debiera centrarse y evolucionar gran parte de nuestro debate político. Al mismo tiempo, si nos fijamos en algunos de los impulsos iniciales para trascender esta agenda, vemos que es relativamente conservadora: asegurarse de que las Big Tech conozcan su lugar en la sociedad, y tal vez, que Europa desarrolle capacidad tecnológica propia o que los estadounidenses reflejen su visión y respeten los derechos o regulaciones europeas de una manera mucho más contundente.

Así que, ¿cuál ha sido la forma más inmediata de trascender esa idea desde la izquierda? Muchas personas de las ramas más radicales pensaban que tal vez el mundo del big data, el de los sensores, algoritmos e infraestructuras permitirían de una forma $u$ otra recuperar y redescubrir la planificación como un paradigma alternativo a través del cual podríamos impugnar la victoria del neoliberalismo. Creo que se han escrito muchas cosas en las últimas décadas, incluso antes de que empezáramos a hablar de big data, pero especialmente esta práctica ha tenido lugar en los últimos diez años más o menos, cuando la información y los datos se convirtieron en un término de discusión pública muy importante. Desde entonces, el foco del análisis se ha centrado en una nueva forma de planificación, por lo que la experiencia soviética no sólo se reinventaría, sino que estaríamos construyendo algo completamente diferente, tal vez trascendiendo algunas formas numéricas o puramente algorítmicas de planificación y moviéndonos hacia otra cosa. Ha habido un enorme debate sobre cómo estos planteamientos podrían conformar un nuevo proyecto de izquierda, de eso no cabe duda. Yo mismo lo he pensado durante un tiempo, pero ahora tengo algunas dudas sobre su viabilidad como proyecto político, no sólo como proyecto tecnológico. Creo que técnicamente podemos debatir hasta qué punto se puede tener una sociedad planificada en este momento, construida de una manera más fácil gracias a la existencia de una ingente cantidad de datos a nuestra disposición y, por supuesto, cómo podría dar lugar a formas más suaves de planificación. Hablamos de hacer simulaciones, una especie de escenarios de análisis... se puede hacer todo tipo de cosas que necesariamente se sumaría a una planificación en toda regla, y que ayudaría a tomar decisiones que no están del todo moldeadas por el mercado.

No obstante, en mi opinión, las posibilidades y prestaciones que ofrece el big data fuera de las lógicas del 
mercado, no entrañan todavía un proyecto político muy emocionante, en parte porque creo que no resuelve muchos de los problemas y desafíos originales a las que se enfrentaron las experiencias comunistas anteriores, particularmente aquellas de Europa del Este, la Unión Soviética, y hasta cierto punto, China. Por supuesto, dichos problemas tienen que ver con la inmensa concentración de poder dentro de un determinado bloque tecnocrático del Estado y, por tanto, la incapacidad de involucrar a los ciudadanos de una manera significativa en la toma de decisiones, donde también existe un ámbito sobre la toma de decisiones en materia económica. En ese sentido, en el fondo del proyecto marxista, al menos en sus manifestaciones ortodoxas, todavía puede encontrarse esta creencia residual de que lo tecnológico y lo económico, a lo que solíamos referirnos como fuerzas de producción, siguen una lógica que es puramente técnica. También que eliminando las limitaciones sobre lo técnico y lo económico impuestas por los imperativos del capitalismo y por la competencia podemos ser capaces de organizar la sociedad de la manera más eficiente. De modo contrario, la toma de decisiones y otras cuestiones políticas sucedería en la esfera propiamente política. Básicamente, esta idea sostiene que se puede involucrar a las personas en los procesos democráticos, pero que ello no debe afectar de una manera u otra a lo tecnológico, lo cual simplemente debe organizarse de acuerdo con los descubrimientos científicos más reciente. Y estoy dando una especie de descripción banal hasta cierto punto, pero también precisa de cómo funciona la lógica detrás de la mentalidad marxista.

Creo que en la formulación original que hizo [Karl] Marx, y también en la adopción posterior de los regímenes que le siguieron, existe una falta de exactitud o un error a la hora de bifurcar la tecnología. Esto es, a la hora de trazar una separación definitiva entre lo tecnológico, que se puede organizar usando métodos científicos racionales, y lo político, que opera a través de la libre asociación de productores para llegar a una determinada toma de decisiones democrática. Para mí, el problema comienza en un nivel aún más profundo, en el paradigma de la producción en sí mismo dentro del marxismo. No voy a entrar en una crítica extensa sobre ello en esta charla, pero creo que hay algunas cuestiones que se pueden adelantar. Si algo han revelado los últimos 10 o 15 años, y creo que la izquierda no lo ha comprendido, es que cuando se quejan, por ejemplo, de que el trabajo digital está siendo compensado injustamente en las plataformas digitales, a lo que generalmente se refieren no es a una actividad laboral real. Quiero decir, para la izquierda, este es un atajo mental a través del cual pueden dar cuenta del hecho de que de alguna manera las firmas digitales han logrado valorizar la actividad creativa de las personas en esas plataformas y han logrado producir valor a partir de eso. No me refiero a valor en el sentido marxista del término, sino a que han logrado extraer datos de esas actividades y a su vez convertir esos datos en inteligencia artificial. Esa sería la visión utópica de la posición descrita. Pero si compras esas premisas, y mucha gente de la izquierda lo hace porque eso es lo que necesitan para articular un paradigma del trabajo digital, inmediatamente te das cuenta de que está sucediendo algo muy interesante. Nuestra actividad artística, creativa, comunicativa cotidiana es productiva, pero no está adecuadamente contenida en el paradigma de producción o, al menos, en la forma concebida inicialmente por Marx: un tipo muy específico de actividad que se ejerce sobre la naturaleza. Si realmente queremos tratar de trascender esta idea y organizar de alguna manera las actividades económicas y tecnológicas por medios racionales y luego aplicar algún tipo de toma de decisiones democrática en la esfera política, si queremos trascender esa dicotomía entre ambas, entonces es obvio que tenemos que partir del supuesto de que todas las actividades no son productivas. Esto también supone hacer estallar este fetiche de la biopolítica con el que muchos teóricos italianos están obsesionados.

Por tanto, la alternativa que propongo trataría de encontrar formas en que nuestro potencial creativo $\mathrm{y}$ nuestra actividad social diaria puedan insertarse en instituciones que serán económicas, políticas o tecnológicas, y que de una manera u otra permita desarrollarnos y reproducirnos como sociedad. Esto abrirá una enorme cantidad de salidas que serán muy distintas a aquellas donde lo único que podemos hacer es averiguar cómo compensar a los trabajadores por el hecho de que la inteligencia artificial les vaya a expulsar de sus puestos de trabajo. Y eso partiendo del supuesto, el cual considero incorrecto, de que los trabajos vayan a ser destruidos. En este momento, el tipo de debate que falta en la izquierda está relacionado con entender qué han revelado los últimos 10 o 15 años de relación con las tecnologías digitales sobre las fallas y errores en nuestros marcos analíticos subyacentes. En este sentido, creo que es imperativo llegar a un punto analítico diferente sobre cómo queremos que funcionen las tecnologías. También necesitamos ser honesto, y no tengo tiempo para entrar en muchos detalles al respecto, pero implica que tendremos que producir una Filosofía de la historia diferente. Al menos, si realmente nos tomamos en serio que el marxismo es algo más que un cuerpo de esa teoría que logra analizar la realidad usando los conceptos que nos llegan, ya sabes, de [György] Lukács o de quien sea.

En realidad, eso no nos dice nada sobre la historia en sí misma. ¿No era esa la parte más radical del proyecto marxista original, la relacionada con su naturaleza predictiva? Nos referimos la idea de que a medida que se desarrollan los modos de producción, también surgen ciertos conflictos, inconsistencias en su avance y clases sociales. En teoría, la interacción entre esas tres categorías lleva a la sociedad a otro estadio, es decir, en el caso ideal, la lucha de clases conducirá a nuevos modos de producción. De hecho, si le preguntas a quienes hoy en día afirman ser marxista hasta qué punto creen realmente en esas premisas y suposiciones, no estoy seguro de cuántos de ellos estarán de acuerdo en que ese devenir [la utopía comunista] va a ocurrir. Y si realmente no crees en eso, entonces creo que estás operando con un aparato teórico muerto que puede producir magníficos ensayos, pero cuyo valor como programa político es mínimo. En ese sentido, creo que no tenemos que pensar en qué podría reemplazar potencialmente el modo de pro- 
ducción como paradigma teórico, sino en si algo debería reemplazarlo como tal.

No dispongo de mucho tiempo, pero voy a dar una pista de hacia dónde creo que deberíamos dirigirnos. $\mathrm{Si}$ analizamos correctamente la respuesta neoliberal al comunismo, las posiciones de Mises y Hayek, especialmente la reacción de este último a toda la literatura sobre la planificación, lo que surge de ella es un replanteamiento muy eficaz del capitalismo como un modo superior de descubrimiento. Básicamente, los neoliberales miran al capitalismo y te dicen que es bueno porque permite descubrir cosas que otros regímenes no pueden, incluidos el socialismo y el comunismo. Realmente, los neoliberales no tienen una posición muy sofisticada en esta batalla o, al menos, la mayoría de ellos. Si lees los ensayos originales que escribió Hayek, incluso en los años 30, para él solo se trata de una cuestión sobre cómo resolver el problema económico correctamente. No hay nada sobre la cultura en esos textos, no hay nada sobre la sociedad - esas cosas se descubrieron posteriormente. Por tanto, la filosofía neoliberal se basa en descubrir cosas que suceden en el mundo y, esencialmente, ajustar la sociedad automáticamente a ellas. Existen ciertos costes a la hora de llevar a cabo este descubrimiento, pero en general sabes que -usando el marco capitalista- hace crecer el pastel para todos [grow the pie]. De hecho, en torno a esta premisa se asienta la aceptación del capitalismo como el sistema más adecuado. Creo que si la gente de izquierda 'fuera' realmente inteligente, lo que 'deberíamos' haber hecho en un principio sería afirmar lo siguiente: «de acuerdo, supongamos que compramos el marco del capitalismo como un modo de descubrimiento mejor que todos los demás». Ahora bien, a continuación, debiéramos escudriñarlo y ver si los descubrimientos que generan son realmente tan buenos como presumen sus ideólogos. También analizar en qué medida esos descubrimientos y el tipo de instituciones o estructuras que los promueven son suficientemente adecuados para sobrevivir a algunos de los mayores desafíos a los que nos enfrentamos, incluida la catástrofe climática. Y llegado a este punto del análisis, si la izquierda tuviera que formular la pregunta de esa manera, y si analizara sistemáticamente los tipos de descubrimientos que promueve el capitalismo y los tipos de descubrimientos que el capitalismo ha subdesarrollado, o sencillamente reprime, terminaría con una visión relativamente crítica del capitalismo. Podemos apreciarlo de manera sencilla, y aquí es donde entra mi crítica del solucionismo, en que el tipo de soluciones que promueve el capitalismo se encuentran en cierto sentido muy truncado. De una manera u otra, todas miran hacia atrás, se refieren a la necesidad de promover la acumulación de capital o estabilizarla. La mayoría de las soluciones que pueden funcionar o ser aceptadas son soluciones que ayudan a que el capitalismo se expanda correctamente. Hasta cierto punto, el solucionismo es la formalización de este proceso.

En mi opinión, estas no son las únicas formas en que podemos descubrir cosas sobre el mundo. Me refiero a prácticas nuevas e innovadoras que son imposibles de monetizar porque no existe un mecanismo formal dentro del capitalismo para descubrirlas y escalarlas correcta- mente. Esto solo ocurre con las prácticas que son rentables para algún emprendedor, pero si alguien descubre algo que no está sometido a la capitalización, o que no lo es a los ojos de algún inversor, aunque sea socialmente útil, ese descubrimiento permanecerá subdesarrollado o se perderá en el vacío de la historia. Y así es como funciona el capitalismo: puedes desarrollar todo tipo de formas de asociación social mutua para que las personas se relacionan entre sí de manera diferente, o inventar todo tipo de instituciones que hagan las cosas de manera diferente porque ponen en jaque, por ejemplo, ciertas reglas y regulaciones relacionadas con los derechos de propiedad. La cuestión es que nunca tendrán éxito. Por ejemplo, existen infinidad de instituciones públicas en la historia que sirven para criticar el paradigma del mercado, como las bibliotecas, las universidades o las oficinas de correos... Todas ellas operan de una forma distinta, se guían por una serie de principios diferentes a que el sistema siga acumulando capital de manera gradual. El problema es que si quisiéramos reinventar algo como la biblioteca en la actualidad, probablemente terminaríamos encontrándonos con que una empresa como Amazon cobraría por analizar cada palabra que leemos en los libros que tomáramos prestados.

Por tanto, [la firma de Bezos] emergería como una institución, amigable, que satisface esa necesidad particular que es leer. En suma, lo que quiero decir es: si examinamos correctamente el capitalismo como un modo de descubrimiento, en lugar de como un modo de producción, y lo hacemos dentro de los términos que los neoliberales mismos han propuesto, observaríamos que el funcionamiento de este sistema es más débil de lo que parece. También que los paradigmas neoliberales tienen una arquitectura bastante precaria.

Evidentemente, cualquier alternativa que queramos articular al capitalismo debería empezar por asegurarnos que la humanidad sobrevive a la catástrofe climática. Por otro lado, cualquier modo alternativo de descubrimiento, si realmente queremos utilizar ese paradigma, tendrá que ser capaz de descubrir e institucionalizar los tipos de prácticas y soluciones que, al menos ayuden a comprender cuál es la gravedad de la situación y de qué manera podemos salir de ella. Este sería un buen prerrequisito básico para un contraparadigma. Pero después tendríamos que pensar un poco en otras dimensiones. ¿Cómo es posible institucionalizar el descubrimiento de nuevos hechos sobre el mundo, prácticas novedosas, o estructuras e instituciones que luego pueden ser constantemente revisables? En última instancia, la verdadera democracia significaría eliminar los impedimentos estructurales para llevar a cabo una revisión de las instituciones existentes para que estas no se naturalicen. Además de eso, y en un plano superior, necesitamos encontrar una manera de que este proceso de descubrimiento perpetuo y constante revisión sea generativa de lo que en el marco antiguo llamaríamos valor. Deberíamos concebir algún mecanismo a través del cual nuestra actividad social diaria creativa no se desperdicie o sea desechada. No podemos dejar que sean monetizadas por el paradigma solucionista de Silicon Valley, sino que debemos asegurarnos de que esta inmensa capacidad creativa que 
todos expresamos [en las plataformas digitales], y que produciríamos incluso de una manera mayor o aún más profunda en otros entornos, se encuentra contemplada en infraestructuras digitales que no estuvieran configuradas para la función de captura. La invención [de nuevos métodos de coordinación social] y [la capacidad de] desestabilización [son requisitos básicos en esta agenda]. Cuando esto ocurra, entonces estaremos en la posición de construir una forma diferente de capturar lo que hoy todavía llamaríamos valor y asegurarnos de que contribuya a la reproducción y al crecimiento de nuestra sociedad. Creo que este sería un paradigma teórico, pero también político, muy diferente. Necesitamos tener una idea clara de qué tipo de tecnologías nos gustaría tener y especificar a nivel normativo cuáles son los criterios correctos con respecto a la propiedad, la plasticidad o la reversibilidad.

Para mí es obvio que la tecnología, y mucha gente lo dice, está politizada y también que este artefacto tecnológico podría estar contribuyendo al racismo, etc. Todo eso se sostiene gracias a que los estudios de ciencia y tecnología están bien aceptados, pero lo que no decimos, lo que no vemos, lo que no hacemos, y mucho menos ponemos en práctica, es la idea de que las tecnologías también ayudan a divulgar, revisar y derrocar dichos arreglos políticos, los cuales antes se revelaban o mostraban como naturales. Basta pensar en el proyecto Science Hub, que muchos de ustedes podrían estar usando para descargar artículos académicos. Si lo piensan bien, esta es una tecnología genuinamente revolucionaria que en cierto sentido tiene profundos efectos políticos: revela que el régimen normal de publicación académica que a menudo damos por sentado es un arreglo justo en la sociedad, aunque en realidad es un [régimen de publicación] profundamente injusto. La herramienta politiza este hecho hasta el punto de llegar a cambiar la opinión pública. De este modo, el antiguo paradigma es derrocado y el nuevo paradigma emerge en su lugar. Todo ella revela que aquellas tecnologías que consideramos completamente normales en nuestro día a día, en realidad congelan y someten el conflicto social. Además, la facilidad con la que aparecen tales tecnologías no es un suceso aleatorio. [Como señalábamos en relación a los procesos de descubrimiento], existen ciertos factores y elementos en nuestra infraestructura tecnológica, o en la política misma, que permiten a algunas tecnologías sobrevivir antes que otras.

Si realmente pensáramos en un tipo radical de sociedad, donde las cosas funcionan de manera diferente, la pregunta normativa que deberíamos plantear con respecto a nuestras infraestructuras tecnológicas es: ¿qué necesita cambiar en el diseño, propiedad o la facilidad con la que podemos revisarlas y reconstruirlas para que haya más proyectos como los de Science Hub? De este modo, podríamos movernos de tecnologías radicales, relativamente instrumentales, hacia tecnologías que disuelven el poder. Sin duda, es gracias a esos proyectos que adquirimos una palanca política adicional a través de la cual se puede crear un tipo diferente de sociedad.
He utilizado el ejemplo de Science Hub, pero podría haber usado fácilmente el de Wikileaks. Podemos argumentar $\mathrm{y}$, por supuesto, podemos ver que, en el mundo actual, la radicalidad de algunos experimentos como éste fue posible gracias a que disfrutaban de alguna suerte de protección procedente de un Estadonación, es decir, no se debía a que una parte de la infraestructura tecnológica fuera por sí misma más o menos susceptible a abrazar una agenda radical. Creo que necesitamos problematizar esa agenda, y lo que he propuesto, tal vez de una manera muy serpenteante y algo confusa, supone vincular este conjunto de nuevos criterios normativos para decidir y diseñar infraestructuras alternativas a fin de llevar a cabo un proyecto político radicalmente diferente. Si no lo hacemos, de no llenar ese espacio de lo político con algo emocionante y que realmente esté a la altura de los desafíos teóricos abiertos a través de los últimos 100 años, terminaremos con una agenda muy poco atractiva que busca movilizar la tecnología para un proyecto político que en sí mismo se encuentra en estado moribundo. En definitivas, más allá de responder a las preguntas sobre cómo se puede articular una política tecnológica propia, o cómo Europa podría reaccionar de manera diferente a EE. UU. o China, desde la izquierda debiéramos pensar un poco más sobre cuál es el contenido real de este proyecto. Por supuesto, resultaría muy fácil optar por refugios intelectuales y decir que nuestro trabajo es proteger a la clase trabajadora. Ciertamente, esa afirmación en sí misma no suena como un proyecto utópico. No tengo nada en contra de crear un algoritmo heredado de años de luchas de clases, en lugar de otros sesgos, pero eso no necesariamente se traduce en un proyecto político.

Nuevamente, me disculpo por si algo de esto fue demasiado teórico o abstracto, pero espero haber indicado que si realmente queremos escapar del capitalismo digital necesitamos entender qué es en realidad el capitalismo no digital. Desafortunadamente, hasta ahora no he visto una comprensión sólida en ninguna parte de lo que este sistema significa. Las reflexiones que versan sobre algunos de estos debates, sobre el socialismo o el comunismo digital, no contienen los avances teóricos radicales que realmente necesitamos para dar sustancia a debates de calado. Estos no suelen ir más allá [de nuestro contexto performativo], sólo tratan de imaginar cómo serían las viejas ideas de izquierdas añadiéndoles plataformas, smart cities o algoritmos. No se trata de predefinir y modernizar esos proyectos, sino de llenarlos de un contenido que actualmente no tienen. Estoy bastante convencido de que, al margen de una agenda defensiva sobre los derechos civiles y el estado de bienestar, la izquierda no tiene ningún otro proyecto. Esta es una nota ligeramente depresiva, pero realista. Cualquier proyecto que emerja debe tener en cuenta ese vacío y llenarlo de contenido antes de presentar algún tipo de plan definitivo [contra el capitalismo] sobre cómo deberían ser un conjunto alternativo de tecnologías digitales. 